\title{
BODILY TRANSLATIONS: \\ THE POLITICS OF PAIN EXPRESSION AMONG INDO-FIJIAN WOMEN
}

\author{
Susanna Trnka
}

ABSTRACT

An extensive literature exists on the relationships between body pain, language, and social communication, much of it focused on the disparities between patient experiences and medical classifications of 'real' pain. A similar tension exists in Fiji where medical personnel in public clinics routinely contend that Indo-Fijian women patients complain of, but do not 'really' experience, body pain. This paper examines translations of women's complaints of body pain in order to suggest some of the roles that these contentious clinical encounters play in state and community processes that ascribe alternative meanings to body pain. Focusing on the ways in which women foster certain kinds of talk of body pain with physicians as well as with one another, I argue that the category of 'unreal' pain, as used by physicians, is a multivalent one, consisting of pain induced by psychological stresses and/or physical, work-related stresses. Hindu women engage in a complementary but distinct discourse that is interlinked with both familial and community political concerns. Women do so by emphasizing links between physical labour and pain as a means of asserting how industriously they work towards fulfilling their domestic and religious obligations. Through their talk of pain, women furthermore engage in wider political discourses of labour and industriousness that are part of national-level political strategies for the recognition of Indo-Fijian rights. IndoFijian women's expressions of pain thus involve not only the communication of distressing bodily symptoms but also indicate women's pride in their labour efforts and their participation in political rhetorics that transcend the local level.

During an early morning tea break at the Nausori Health Centre (NHC) in Fiji, Dr. Dovi and I are chatting together in the staff tearoom when his colleague Dr. Singh, bursts into the room. Visibly frustrated, Dr. Singh shakes her head and loudly complains to everyone in the tearoom that all she is hearing from 
her patients today is 'all this pain here, pain here, pain here!'

'It's because of the coup', Dr. Dovi says, 'They are all -'

'No,' Dr. Singh interrupts him, 'It's always [been] like that. All these housewives complaining.'

It's been almost a month since the May 19, 2000 coup when a wave of violence began spreading through Nausori and Suva. Like many of the area's residents, the health centre's physicians, nurses, support staff and patients are all feeling on edge, wondering when the political turbulence will stop. But Dr. Singh is correct that even before the 2000 coup, she, Dr. Dovi, and their colleagues at NHC frequently expressed frustration over what they described as 'housewives wasting their time' with seemingly never-ending symptoms of pain. In my observations and conversations with NHC's physicians, both before and after May 19th, they also clarified that it was not just 'housewives', but more broadly Indo-Fijian women, who they saw as at the heart of the health centre's overcrowding problem.

The pressures of political violence aside, there are a lot of factors that make life difficult for a physician working at NHC There are the daily stresses of a high physician to patient ratio, shortages of medicines and bandages, the occasional absence of running water, and unhealthy conditions caused by working in a building badly in need of repair. Under these conditions, physicians and nurses at NHC attend to patients with all manner of physical conditions. For the most part, I observed how they respond to their patients and their overall work environment with great dedication and perseverance. But on occasions, NHC's physicians react by expressing great frustration, usually over the issue of patient overcrowding. Their ire is not, moreover, directed against all the patients who stand outside their office doors, but at one group in particular - Indo-Fijian women whose primary symptoms are body pain. Depicted by Indo-Fijian and indigenous Fijian physicians and nurses alike as 'wasting' precious clinic resources by complaining about 'unreal pain', these women often receive cursory examinations and are quickly dismissed out of the consultation room and off to the pharmacy, clutching a prescription for free paracetemol (acetaminophen). Yet many of them return again and again, waiting for hours for another chance to secure a few minutes with a physician.

This paper takes consultations between physicians and Indo-Fijian women in pain as its starting point. I begin by comparing two perspectives on physicians' exams and diagnostic assessments of women in pain. First, I briefly con- 
sider the point of view of NHC's physicians bent on discriminating between 'real' and 'unreal' pain and, as a corollary, trying to figure out what to do with all of these women complaining of unreal symptoms. ${ }^{1}$ I then move onto the perspectives of Indo-Fijian women who vociferously refute doctors' attempts to translate away their pain, but who also flock to NHC despite their often cursory dismissal. In assessing what is at stake for these women, I show how their expressions of pain and their desire to secure a prescription are associated with the sidelining of women's labour within their conjugal families and in their neighbourhood, religious communities. ${ }^{2}$ Finally, I examine some of the political linkages between women's local level struggles for recognition of their labour and national-level political strategies for the recognition of IndoFijian rights. These interconnections become evident when we consider the rhetorical debates between taukei (indigenous Fijian nationalist) politicians and Indo-Fijian community leaders during the 1987 and 2000 coups. As has been widely noted, the political upheavals of 1987 and 2000 depended upon a groundswell of support for a brand of indigenous Fijian nationalism which vilified Indo-Fijians as 'foreigners' who have greedily usurped Fiji's bounty (Trnka 2002a, 2002b, 2002c; Lal 2000, 2002; Kelly and Kaplan 2001). The counter rhetoric voiced by Indo-Fijian community leaders and their supporters revolved around Indo-Fijian contributions to the Fijian economy through their physical labour and thus ties in with the themes of the body and labour that we will be examining here (see also Trnka 2002b, in press). In other words, by beginning with a micropolitics of translation - interpreting what is said and left unsaid within the examination room - and then moving towards a wider analysis of the concept of the Indo-Fijian body as a site of identity and a source of discursive resistance to anti-Indian rhetoric, I intend to show how Indo-Fijian women's expressions of pain involve not only the communication of distressing bodily symptoms but also indicate women's pride in their labour efforts, their invocations of institutional authority in their negotiations of familial and community valuations of labour, and their participation in political rhetorics that transcend the local level.

Throughout, I engage with anthropological scholarship on pain as well as literary critic Elaine Scarry's landmark book, The Body in Pain (1985). Since its publication two decades ago, Scarry's text has had a monumental impact on medical anthropology, particularly on studies of chronic pain, and on the anthropology of suffering. Most of the scholarly attention has revolved around Scarry's assertion that a person in pain lives in a world separated from others, a world 'unmade' by pain (Scarry 1985:4, 19). Numerous ethnographic treatments of pain have confirmed Scarry's insights into pains' potential to radically alienate the person-in-pain from the rest of his or her social world (Dan- 
iel 1996, Jackson 1994, Good 1994, 1992, Das 1996, 1990, and Kleinman 1992, 1986). Many of the same studies have, however, also shown that in some cases, communication despite, or even via pain, is indeed possible. As E. Valentine Daniel, Byron Good, Veena Das, and others who have focused on the everyday lives of those subjected to physical and psychological traumas (ranging from communal violence to chronic pain) have demonstrated, in some cases languages of pain act not only to initially alienate, but also to later re-integrate subjects into their social world (Das 1996, 1990; Kleinman 1992; Desjarlias 1992; Brodwin 1992). Das, for instance, documents how pain and trauma can, for some, become the shared catalyst for new community identities and revised approaches to the rhythms and meanings of everyday life $(1996,1990)$. Kleinman likewise refers to pain as an 'idiom of distress' thereby suggesting the possibility of communication through expressions of pain (1992: 170).

Taking seriously Das' and Kleinman's suggestions to think of articulations of pain as social and communicative acts, I want to examine the range of possible meanings to which Indo-Fijian women's expressions of pain might refer and why these women feel compelled to enter the medical clinic to voice them. In focusing on how symptoms of body pain are 'translated' in the clinic and beyond, I will touch on three areas: linguistic communication and the use of multiple languages (Fiji Hindi, English, and Fijian) in physician-patient interactions; bodily communication and the visual 'mapping' of symptoms; and finally and most importantly, the interpretations and meanings assigned to pain in medical, familial, community, and national political discourses. I have chosen to use the concept of 'translation' in order to highlight the moves made not only between the multiple languages of linguistic and bodily communication but also the various political meanings ascribed to body pain. ${ }^{3}$

\section{HEALTH CARE AT THE NAUSORI HEALTH CENTRE}

Nausori is a town of approximately 15,000 people, located on the island of Viti Levu, just $20 \mathrm{~km}$ outside of Suva. According to the 1996 census, the population of the Central Division of which Nausori is a part is approximately $33 \%$ IndoFijian and 59\% indigenous Fijian, with the remaining $8 \%$ categorized as belonging to 'other' ethnic groups. ${ }^{14}$ The majority of the Indo-Fijian inhabitants are the descendants of indentured servants, or 'girmitiyas,' who were brought to Fiji by the British colonial government in the late 1800 s and early 1900 in order to provide the labour for Fiji's sugar industry which quickly became one of the pillars of the Fijian economy. ${ }^{5}$ As in other parts of Fiji, Indo-Fijian residents in Nausori belong to a number of religious affiliations, including Hindu (Sanatan and Arya Samaji), Christian (of various denominations), and 
Muslim and Sikh. The majority of them are, however, Sanatan Hindu and this research focused predominantly on Sanatani women.

Indo-Fijian in Nausori, and elsewhere in Fiji, understand and use a range of languages. Due to the prevalence of English in the educational and in governmental and bureaucratic offices, all contemporary Indo-Fijians, like all indigenous Fijians, have significant exposure to English. In Nausori, Indo-Fijian men of all ages and young Indo-Fijian women are fluent in English. English skills among middle aged and older Indian women vary from fluency to little or no comprehension. Very few Indo-Fijians in Nausori spoke any Fijian, and, as far as I am aware, all those who did were men. Regardless of their linguistic capabilities, for the most part, Indo-Fijians in Nausori prefer to speak their native language of Fiji Hindi. Fiji Hindi - or 'Fiji Bat', literally 'Fiji language' - is most closely related to the Bhojpuri and Avadhi dialects of Hindi that are spoken in northeast India ( $\mathrm{Lal}$ 2004). Even though it is based on standard Hindi, Fiji Hindi has its own grammatical structure and is often, but not always, transliterated instead of written in the Devangari script, as is standard Hindi (Moag 1977) ${ }^{6}$. The language draws most of its vocabulary from standard Hindi, but also includes some of its own unique terminology and incorporates English, Fijian, and South Indian expressions (Lal 2004). The majority of Indians in Fiji grow up speaking Fiji Hindi at home, ${ }^{7}$ but the more formal dialect of Hindi (standard or shud ('pure') Hindi) is used in formal speeches, in the press, on the radio or on TV. ${ }^{8}$ While Nausori's Indian residents understand standard Hindi, know some English, and, in a few cases, know a little Fijian, the majority of them felt most comfortable communicating - about their health and other matters - in Fiji Hindi.

The Nausori Health Centre is a government-sponsored medical clinic that was first built under the British colonial government in 1963. Its current services include basic medical care, ongoing treatment for diabetes, cardio-vascular health and asthma, vision care, maternity services, dentistry, and emergency services. The centre serves not only town residents but also the surrounding population, extending its health services to a total of about 68,000 people (Salusalu 2000). With between two and four physicians on outpatient duty on any given day, approximately 1,00o outpatients a week pass through the clinic (Salusalu 2000). In 1999 and 2000 I spent 12 months living with residents of this area, six months of which were devoted to clinical observations of indigenous Fijian and Indian medical practitioners in the Nausori Health Centre, attempting to understand patients' and physicians' perspectives on body pain. 
It's seven in the morning and the benches outside of the NHC are already overflowing with Fijian and Indo-Fijian men and women waiting anxiously for their chance for a free medical consultation. Despite the crowd gathering outside, the centre's doors won't open until about an hour later. In the meantime, an orderly begins to hand out numbered tickets, usually 150 to start off. Once a patient's number is called, he or she will first see a triage nurse, and then line up outside one of two or three doctors' offices. I estimated that once the centre is officially open, a patient's waiting time for an initial examination with a physician can last anywhere from 30 minutes to over $1 \frac{1 / 2}{2}$ hours, following which most patients spend approximately $5-15$ minutes being seen by a physician, before getting into yet another line at the pharmacy window. But arriving early, before the 150 tickets are handed out, is the only way of ensuring a consultation that day as late arrivals, unless deemed an emergency case, are frequently sent home. Outpatient examinations usually run throughout the morning and into the early afternoon. By the time all of the patients have been initially examined, sent off for x-rays or other tests, and returned for further consultation following their test results, it is often around 2 or 3 p.m.

A patient's progress towards a physician is closely coordinated by the nurses and the orderlies who call out the ticket numbers. The first step is the move from the outside benches to the inside waiting room. Here, one of the triage nurses conducts an initial assessment. Sitting at her desk in the centre of the room, in full view of other waiting patients, the nurse elicits a brief description of the patient's ailment, takes his or her necessarily vital statistics, and decides which cases need to go directly to the emergency room, or to the dressing room for the cleaning of wounds or application of bandages. Many patients whisper to the nurse so as to maintain some level of privacy.

Frustration due to delays in seeing a doctor is common. There are frequent attempts to move inside the centre before one's number is called, or to skip the triage nurse altogether and join one of the lines outside the doctors' offices. The orderlies in charge of handing out numbers are also in charge of maintaining clinic rules and heated arguments between patients and orderlies over the need for care versus the need to respect clinic procedures are not uncommon. Occasionally they devolve into shouting, and once I witnessed a physical altercation. While some of the doctors' offices have actual doors, others are separated from the line of waiting patients by curtains and waiting patients often impatiently peek in and observe the proceedings taking place ahead of them. 
When patients enter the doctor's office, it is not uncommon for them to come in with family members who are also requesting medical care. The doctor usually tries to quickly ascertain each individual's symptoms and then send them off for any necessary tests or usher them out with advice on how to treat their conditions and, more often than not, a prescription for medicine or multi-vitamins that they can obtain for free from the clinic pharmacy.

As in most public places in Fiji, the medical centre is a tri-lingual site in which communication, and miscommunication, occurs in various languages. During the period of my observations, all of the triage nurses were Fijian and in addition to speaking English and Fijian, they had rudimentary language skills in Fiji Hindi. Initial examinations were conducted in a mixture of languages, often with a playful awareness of the need to cross linguistic boundaries. Patients of any ethnic background might find the nurses responding to their description of their aliments with a hearty, 'accha, vinaka!' - accha being the Hindi for 'good,' and vinaka the Fijian for 'thank you.'

While the triage nurses self-consciously poke fun at their attempts to communicate in all three languages, physicians often require more lengthy dialogues with their patients and are sometimes caught short by linguistic barriers. Patterns of communication between patients and doctors tend to vary according to their ethnic identity and language capabilities and most patients express a marked preference for being seen by doctors of the same ethnic group due to ease of communication. Of the four doctors whose consultations I was able to observe, one senior Indian doctor was fluent in Fijian (as well as in Fiji Hindi and English), a junior, Indian doctor had no Fijian language skills, one junior Fijian doctor had rudimentary Hindi skills that allowed him to ask simple questions about symptoms but not to carry out lengthy conversations, and a second, junior Fijian doctor had extremely limited Hindi skills which I sometimes observed lead to misunderstandings of patients' complaints.

Communication between patients and practitioners also depends on their cultural knowledge of one another. I once, for instance, observed a very young Hindu woman with a bindi, a red circular mark on the forehead worn in this area only by married Hindu women, blush with humiliation and have great trouble responding when a Fijian doctor, who needed to ascertain the nature of her gynaecological problem, asked her if she had a 'boyfriend' and was sexually active. It is also no doubt easier for a Hindu woman to ask a Hindu doctor for medication to stop her period so she can be ritually 'clean' for a celebration such as Ram Noumi (the festival in honour of the birth of the god Ram) then it is for her ask a Fijian doctor. Likewise, Fijian doctors show 
an understanding and respect for Fijian 'bush remedies' or natural medicines while some Indian doctors actively attempt to shame Fijian patients who use them.

Where verbal communication is limited, both Indian and Fijian patients rely on visually presenting their symptoms either by revealing body parts in need of care, in the case of wounds, for example, or by bodily mapping out their symptoms. Faced with a non-Hindi speaker, Indo-Fijian patients who cannot speak English or Fijian, tend to point to a body part and repeat a single word, such as 'pirai'(it hurts). Fijian patients who do not speak English and encounter an Indian doctor who does not speak Fijian, often wordlessly point to areas on their body. While these techniques are more vital when there are linguistic barriers, such forms of 'body mapping' are commonly utilized even when patients and practitioners share the same language.

While miscommunications do occur, in most cases patients are able to see, often repeatedly, doctors with whom they can readily communicate. Return visits to the same doctor furthermore result in the establishment of knowledge and trust between the doctor and the patient. It is not uncommon for the doctor to live in the same geographic area and to be friends with or to know friends of the patient. ${ }^{9}$ In these cases, doctors are well acquainted with the details and history of the patient's family life and social history.

DEALING WITH 'PROBLEM PATIENTS' - INDO-FIJIAN WOMEN IN PAIN

Indian women make up approximately $11 \%$ of the adult population of the greater Nausori area (1996 census), but in my observations, they compose about $75 \%$ of the adults presenting body pain as their primary reason for seeking medical care at NHC. The range of their symptoms includes backache, headache, aching arms, shoulders, and legs. Most of these women are in their late twenties or older, and many of them are return patients, well recognized by the doctors who treat them.

While the May 19, 2000 coup certainly raised stress levels among all of Fiji's residents, most doctors at NHC did not note a significant change in the number of women or the symptoms they presented. My own observations following the coup confirmed this, though my access to the centre at that time was more limited than it had been before the coup, due to the ongoing violence and threats of violence in Nausori. Doctors, however, informed me that if anything, the overall numbers of patients seeking care dropped because people were afraid to venture into Nausori Town. The day of the coup, 
shops in Nausori Town had had their windows smashed and had lost goods due to looting. A bridge leading from the town, which is about two minutes walk from the clinic, was also the site of a police and rebel shoot out. Along with the imposition of a curfew, such incidents resulted in many Indo-Fijians restricting the time they spent outside of their homes. (For details on IndoFijian responses to these and other events of the 2000 coup, see Trnka $2002 \mathrm{~b}$ and 2002c). Though the numbers of patients may have momentarily gone down immediately following incidents of violence, doctors at NHC noted little change in the patients they saw as the months of political turbulence dragged on. Both before and in the months following the May 2000 coup, Indo-Fijian women patients turned to NHC's physicians to articulate their pain and to look for pain relief.

Physicians' and patients' interpretations of what is at stake in these medical encounters are, however, quite divergent. Let us begin with the perspectives of the medical staff. One physician at NHC described the main cause of the centre's overcrowding as being due to 'a lot of Indian women ... coming in, even if they have nothing wrong [with them]. He added that most of these women would not leave until they receive a prescription. Another doctor told me, 'Indian patients complain so much of pain [that it] is hard to work out if it is real.' These were just a few of many comments in which doctors expressed their concerns and frustrations in having to make distinctions between patients who are or are not in need of care, who have actual or non-existent pain. The patients they single out in their criticisms are almost always Indo-Fijian women. ${ }^{10}$

While doctors steer clear of explicitly voicing their frustrations over 'real' and 'unreal' pain to their patients, their sentiments are evident in their examinations of women who are considered 'problem patients.' On a busy day, Dr. Singh had seen a number of patients who requested medication that she did not feel was appropriate. When an older Indian woman walked into the examination room. Dr. Singh turned away from the patient to speak to me, in English, which she correctly assumed the patient would not understand. 'Sometimes you just don't feel like asking [them] any questions,' Dr. Singh said, 'It is so irritating.' She then conducted a quick examination of the patient, who complained of body pain. Dr. Singh began to fill out a prescription slip and said, again to me, 'Sometimes you can't know the extent of the pain. It's intensity. Is it really real?' She handed the woman the prescription without a word and the patient exited the exam room. 'See, they just want a prescription', Dr. Singh said to me. 'With these people, they will never be good. You ask them how they are and always something is wrong. A Fijian could be dying and they 
would say they are all right. ${ }^{11}$ Indians, they just want medicine. If you try and tell them something [else is the problem], they don't listen. They look at you as if you are dumb.'

At first, many of the comments about 'unreal' versus 'really real' pain made by physicians such as Dr. Singh seem to coincide with Elaine Scarry's assertions of the disbelief a person feels when confronted with pain in another's body. Scarry argues that 'physical pain does not simply resist language but actually destroys it, bringing about an immediate reversion to a state anterior to language' (1985: 4). In doing so pain, according to Scarry, causes an 'absolute split between one's sense of one's own reality and the reality of other persons' (1985: 4). It is important to remember, however, that while Scarry focuses much of her documentary evidence on acute pain that results from activities such as torture and warfare, she goes on to propose some very broad speculations about the experiences of physical pain in general. Scarry's insights into pain have also been adopted by anthropologists whose work ranges from studies of pain among victims of rape and war trauma (Das 1996, Daniel 1996) to the experiences of patients with chronic pain such as temporo-mandibular joint disorder (Good 1992).

If one were to accept the application of Scarry's insights to cases of chronic pain, it would suggest that because pain patients are unable to adequately communicate the sensations in their bodies, doctors do not comprehend that their patients are actually in pain. Indeed, initially I took NHC's doctors' statements about the unreality of patients' pain to indicate that they considered the bulk of Indo-Fijian women patients reporting body pain to be malingerers. This also fits in with the fact that many of NHC's doctors initially rely on visual indicators, such as wounds, swelling, or broken bones, rather than patient's verbal communications, to assess if their pain is 'really real.' If we do a comparison with pain assessments in the US, where there is a long history of anthropological studies of clinical treatments of pain, we find similar assessments being made. It has been well documented, for example, that among American physicians, pain that is caused by a visible injury is usually accepted as 'genuine' (Jackson 1994). Many kinds of pain, particularly chronic pain, do not, however, visibly manifest themselves on the body and it is not unusual for American physicians to question whether such invisible pains 'really' exist or are illusory (Kleinman 1992, Jackson 1994). In Fijian clinics such as NHC, the privileging of visual indicators over verbal accounts is strengthened by the fact that, as described earlier, verbal communication between patients and doctors who do not always share the same language(s) in common is sometimes reduced to only visual evidence of illness. In other cases, even when 
linguistic communication is possible, visual 'mapping' of symptoms remains a very common method of communication.

However, the more examinations I observed, the clearer it became that whether or not pain is translated as being 'really real' at NHC depends on a lot more than whether or not doctors can see evidence of it or even whether or not they think it actually exists. At NHC, the distinction between pain that is 'unreal' and pain that is 'really real' has little to do with the bodily experiences of Indo-Fijian women patients but is in fact a distinction between pain that physicians can and cannot successfully treat within the clinic. In fact, doctors often had long, in-depth discussions with women about how to treat pain that they later referred to, to one another or to me, as being unreal. In all of these cases, the pain was deemed unreal not because doctors didn't believe in its existence, but because it was due to either psychological stress or to physical, work-related stress - both causes that doctors were unable to effectively address within the confines of the medical clinic. In other words, because the origins of the pain were outside the bounds of anything that they could influence as a medical clinician, doctors referred to such pain as not being real (for more details on how such assessments are made, see Trnka n.d.).

Indo-Fijian women, however, share different interpretations of their pain. In their interactions with physicians, they welcome diagnoses that explain their pain as caused by physiological factors or by work-related stress, and often promote the latter explanations themselves. In general, however, women resolutely refute doctors' interpretations of their pain as either psychological or caused by family problems (Trnka n.d.). I will come back to why this is the case, but for the moment, I want to turn to another puzzle, namely why women would want to continually return to a site in which their pain is dismissed.

In trying to understand why women flock to the medical clinic, I found myself reassessing what Indo-Fijian women patients derive, or are hoping to derive, from these interactions. They are, after all, not only after pain relief. They can obtain the same paracetemol for a small cost from the corner store without waiting in line for hours, or in some cases, paying for bus fare that costs more than a few pills of paracetemol. If we take another look, could we derive yet another set of meanings out of this interchange? I would like to suggest, following the work of Veena Das $(1996,1990)$ and Arthur Kleinman (1992), that expressions of pain are indeed a communicative act that has the potential of communicating meaning, but that these meanings are not always limited to expressions of distress. In the case of Indo-Fijian women complaining of body pain, in some cases, their articulations of pain are as much an assertion of 
their labour as they are an expression of their suffering.

TRANSLATING EXPRESSIONS OF PAIN WITHIN THE POLITICS OF LABOUR

Indo-Fijian women do, as physicians point out, talk a lot about body pain. Nor is women's talk of pain limited to the medical clinic. In temples, in stores, in domestic spaces, and on street corners, women matter-of-factually relate to one another their symptoms of pain. So much so that evocations of pain sometimes form part of women's greetings to one another. Following the standard greeting of 'Kaise hain?' or 'How are you?' a woman of middle age or older will frequently reply, 'I'm fine, but my back is aching or my legs are aching' (Trnka 2002c).

Very rarely are these comments seen to merit further elaboration, but on the occasions in which women are more vocal about their pain, most often their symptoms are linked to the stress of physical labour. This is particularly so after long, intensive religious festivals, such as Diwali (a multi-day festival celebrating the Hindu New Year) or Ram Noumi when women are apt to remark how tired they are and how much their bodies ache from all the work they'd done. At the height of the Diwali celebrations, for example, one woman complained to a sympathetic friend how much her back hurt, and then commented, 'Acchā jab Diwali khatam hai, dui hafte ham ghar săf kiya! (It is good that Diwali is ending, [because] I've been cleaning the house the last two weeks!)'. Her words, and similar statements made by other women, echo in my mind the complaints of many American academics, corporate workers, stay-at-home mothers, and high school and university students who proudly complain of how 'stressed out' and overworked they feel, holding up their lack of sleep or intensive activity as a badge of honour. Hindu women in Fiji likewise use their bodies to assert their productivity, but this time it is through a language of pain rather than the idiom of 'stress.'

This productivity is important to both women's families and to their extended religious communities. All of the women I knew who complained of chronic body pain were married, or widowed, and living with their conjugal relatives. Within their conjugal families, Indo-Fijian women are often valued and judged according to their labour (Gill 1988). Many women, furthermore, struggle with high workloads, often without much social recognition. They may be 'only housewives', as one middle aged woman lamented to me, but in addition to their housekeeping duties, they maintain vegetable gardens on which their families rely, help out in the family business, assist their children in their education, and devote considerable labour to community religious undertakings. 
Others add to these duties their paying jobs, working from home as tailors or in child care, or holding jobs as teachers, clerical workers, machinists in garment factories, etc. Because their labour does not often receive the public recognition that is accorded to men's (Trnka 2002c), they often feel the need to assert their productivity to other members of their families and to the wider, religious community whose members frequently make moral judgments about how hard people work. Body pain is one, socially acceptable, way in which women can highlight their labour.

Consider, for example, the case of a forty-five year old woman named Arjuna. At a local women's Hindu prayer group, I watched as Arjuna sat down on the floor with a hand dramatically pressed against her lower back. 'Hamār gor pire, side pire... ham kal Western side se aya' ('My legs are paining, my side is paining ... yesterday we came back from Western side'), she said, in reference to a visit to the other side of the island to attend a family funeral. The women assembled around her nodded.

In this brief exchange, Arjuna established herself as a moral woman who undertook the long journey to Western side, about 4 or 5 hours drive by private car, in order to fulfil her family obligations. She was, furthermore, presently back on the floor, praying with the prayer group despite her obvious grimace of pain. By nodding, the other women not only validated her statement of body pain, but also her underlying statement that she was correctly fulfilling her duties to her family and to the prayer group.

In other situations, body pain is used not only as a bid for the recognition of fulfilling one's obligations but also as a tool for negotiating work loads within families and in neighbourhood groups. Very often women use pain and tiredness to either indirectly indicate the amount of labour they have already undertaken, or to excuse themselves from taking part in further activities. If, for example, a woman's participation in her local prayer group is being questioned, she might rely on body pain and illness symptoms to excuse her inability, or unwillingness, to contribute more of her labour. Women would sometimes say they couldn't join others to clean the temple, cook the meals eaten at prayers, string flower garlands, or attend prayer services because their legs hurt, their back hurt, or they had a headache. Such statements not only excused their absence but also suggested that they could not cope with having more religious or domestic labour sent their way as they were already working too hard.

All of this interconnects with the broader issue of how Indo-Fijians, and the Indo-Fijian body, are perceived as part of the Fijian nation. Since the coups 
of 1987 and more recently the political turbulence and violence of 2000, the status and safety of Indo-Fijians in Fiji has been under increasing threat (see among others, Kelly 1998; Kelly and Kaplan 2001; Lal 1992, 2002; Trnka 2002a, 2002 b, 2002c, in press). Renewed calls for Indo-Fijians to be viewed as 'foreigners' and encouraged to leave Fiji have led to a rise in violence against Indians, their homes and properties, and their businesses. To counter the image of Indo-Fijians as foreign usurpers of Fijis bounty, Indo-Fijian community leaders and others have highlighted the many contributions that Indians have made to Fiji's economy, initially as an imported labour force in Fiji and later as free labourers (Trnka 2002b; Kelly 1992). This discourse on the importance of the Indo-Fijian labouring body has been propelled into the limelight as a means - perhaps the means - of defending Indo-Fijian rights to stay in Fiji (on its uses following the 2000 coup, see Trnka 2002b, in press; for an analysis of this and similar political discourses prior to the 2000 coup, see Kelly 1991, 1992, 1998). Evocations of the symbolic associations of the land of Fiji have most often been linked to indigenous Fijian identity; this is particularly so through the indigenous Fijian concept of 'vanua' by which the soil and land of Fiji become a central pillar of indigenous Fijian identity (Abramson 2000). But increasingly there have been attempts to symbolically link land to IndoFijian rights. In Indo-Fijian political discourse, the figure of the Indo-Fijian farmer tilling the soil, sometimes described as 'sweating' or 'bleeding' into the earth to make it grow, has been used as a rallying point around which IndoFijians can assert their physical interconnection to Fiji (Trnka 2002b, in press). This image is further strengthened in Indo-Fijian fiction, which is replete with representations linking the (male) Indo-Fijian body to the Fijian land (see Trnka 1999, in press). What is left out of this popular discourse is the female body. While Indo-Fijian women laboured, from indenture onward, next to their Indo-Fijian husbands, brothers, and sons, their bodies and the products of their labour are left mostly in the shadows. ${ }^{12}$ Expressions of body pain, however, are one way by which indo-Fijian women can evoke from themselves a place as labourers, working as intensely as men to promote Fiji's future.

In many ways, this discussion leads us back to Scarry's opus. Despite the acclaim her book received, the second half of Scarry's text is rarely remarked upon. ${ }^{13}$ In this section, Scarry looks at how the world is 'remade,' arguing that it is through creativity combined with human labour that pain is 'collectively translated' into a socially-valued object. As she puts it, 'In work, then, pain is moderated into sustained discomfort; and the objects of imagining, though individually moderated into fragmentary artefacts, are collectively translated into the structures of civilization .....' (1985:172). 
Scarry focuses her remarks here on the relationships between the imagination and the material products of labour. With the exception of the quote above, she distances herself in this part of her argument from her initial interest in the 'body in pain.' But it is precisely the body in pain - and often not a body in 'sustained discomfort' but a body experiencing the kind of chronic pain that repeatedly drives sufferers towards a search for relief - that needs to be invoked here. Rather than suggesting that work alleviates pain, pain itself needs to be interpreted not as something that alienates the sufferer, but as a part of the social relations of labour.

In fact, where the material products of that labour do not receive adequate social recognition, it is the body through its pain that clamours for attention. As feminist scholarship has so lucidly shown, women's work is often devalued precisely because the products of women's labour are seen as somehow 'natural' rather than 'man-made' (Romero 1992, Oakley 1974). The objects of women's creation - be they clean laundry, a well-fed husband and children, flower garlands for weddings and funerals, etc. - do not speak for themselves. Because of this, Indo-Fijian women are using their bodies and their body pains to assert their position within the division of labour. Their body pains lend another voice to the muffled representations of their labour that exist within the objects they have produced.

\section{ON THE GROUNDS OF INSTITUTIONAL AUTHORITY}

But why voice these assertions to their physicians? If expressions of body pain, in their widest translation, have as much to do with issues of labour, as they do with the physical sensations of discomfort, this still does not answer why these communications should be expressed through clinical interactions.

In trying to answer this question, I do not wish to overlook the pragmatics of women's medical encounters. Most women in pain wish to alleviate their suffering, no matter what they might also, intentionally or unintentionally, be communicating through their symptoms. They therefore enter the medical examination with the simple aim of wanting to find a solution that will get rid of their pain. But by analysing their interactions with physicians, it becomes clear that they often have a second aim in mind, which is to get recognition for their symptoms. These two motives - pain relief and pain recognition may or may not be simultaneously satisfied by the wordless handing over of a prescription. The prescription, after all, grants women access to free painkillers. But it is more meaningful than that. As already noted, one doesn't need a prescription for paracetemol which can be bought relatively inexpensively at 
the local pharmacy, and without the hours of waiting.

Just as important as its function for obtaining actual medication, is the prescription's role as an official document which validates women's body pain. If necessary, the act of receiving a prescription enables women to translate doctors' disbelief of their pain into an affirmation of their symptoms; the fact that a doctor responded by granting them a prescription is used to gain further validation of their pain from family and community members, some of whom may accompany the women to the clinic, or see them there, especially as they wait outside. Through the act of receiving a prescription, women can thus lend further credence to their assertions that they are already doing enough work. This is also the reason why women show such opposition to physicians' assertions that their body pain might result from familial pressures or from other psychological causes. To accept such an aetiology would imply that they are not fulfilling their duties in their families and communities. Instead, women actively reject this possibility, using body pain as an idiom to assert to others that they are doing more than their share of the work. The prescription then further validates women's pain and lends an aura of authenticity to their claims that they are contributing to domestic and community labour.

In conclusion, Indo-Fijian women's assertions of body pain are as much commentaries on their physical labour, as they are expressions of their bodily states. In a political context where Indo-Fijian men's bodies and their productivity are an important political bargaining card, Indo-Fijian women partake in a complementary means of highlighting to their families and religious communities their own contributions to labour. Regardless of what physicians think about the 'reality' of their pain, physicians' responses to women validate these assertions through the act of granting them prescriptions, and in doing so imbue them with an added authenticity that women take with them when they exit through the clinic's doors.

NOTES

1 A lengthier discussion of physicians' responses to Indo-Fijian women's expressions of body pain appears in Trnka n.d. For more on Indo-Fijian women's interactions with physicians, see Leckie's recent analysis of physicians' responses to an 'outbreak of hysteria' among Indo-Fijian schoolgirls in 1968 (Leckie 2004), and Gill's PhD thesis on Indo-Fijian women's health strategies and uses of medical services (Gill 1988).

2 With the exception of residents of urban areas, many Hindus in Fiji live in neighbourhoods or settlements that cultivate a 'gaon' or village ethos, relying on 
pooled labour and face-to-face interactions to sustain religious life (see Trnka 2003).

3 The argument that follows is indebted to Donald Brenneis' work on Indo-Fijian modes of indirect communication (Brenneis 1984, 1990).

4 The figures for all of Fiji are 51\% indigenous Fijian and 44\% Indo-Fijian (1996 census).

5 Many contemporary Indo-Fijians refer to themselves in English as 'Indians', while government documents and the social science literature tend to use the terms 'Indo-Fijian' or 'Fiji Indian.' In this paper I will use both 'Indo-Fijian' and 'Indian' interchangeably.

6 Since my initial language training was in standard Hindi, during my clinic observations I automatically wrote down dialogues that took place in Fiji Hindi in Devangari script. One of NHC's Indian physicians once asked to see what I was writing. When I showed him my notes, he remarked that I might as well have been writing 'in code,' as he had never been taught Devangari script, even though he was tri-lingual and fluent in Fiji Hindi, Fijian and English.

7 There is also a sizeable Gujarati community in Fiji who speak Gujarati, in addition to other languages. A number of Indo-Fijians originate from South India and for some of them, their first languages may include Telugu, Tamil or Malyali, though the rates of retention of South Indian languages vary. For more on the use of South Indian languages in Fiji see the work of France Mugler (for example, Mugler 1998.)

8 Recently, a number of Indo-Fijian scholars have written of their difficulties mastering standard Hindi, given the more informal dialect they grew up speaking (see for example, Lal 2004; for the first novel written entirely in Fiji Hindi see Subramani 2001).

9 Contrary to Gill who found that doctors in the Sigatoka region often used standard Hindi rather than Fiji Hindi in order to 'emphasize authority and class differences between doctors and lower class Indo-Fijians' (1988: 49), my observations in Nausori revealed the opposite. I found that many doctors put more than a little effort into establishing rapport with their mostly lower- and middleclass patients. Both doctors and patients often make reference to and joke about situations or people they know in common. Doctors also go to great lengths to use colloquial terminology for descriptions of symptoms and illness con- 
ditions that their patients are sure to understand. Often the closeness of their relationships is reflected by the use of fictional kin terms. Doctors frequently refer to older Indian women as 'Nani' (mother's mother) and in return are called 'Baitha' (son) or 'Baithi' (daughter). Among doctors and patients who are about the same age, terms such as 'Bhai' (brother) and 'Baihni' (sister) are commonly used.

10 These sentiments are not restricted to doctors in Nausori. Medical professionals I spoke with at the Colonial War Memorial hospital in Suva shared in this opinion, and Gill also records similar comments by physicians in Sigatoka (1988).

11 Many physicians complain that indigenous Fijians compose a second category of 'problem patients', not because they clog up the medical system but because they are 'late presenters' who often do not request medical care until their symptoms are quite pronounced, making their treatment more difficult.

12 While women's work is largely overlooked in Indo-Fijian public discourse, it has received attention in academic scholarship. On Indo-Fijian women as indentured labourers, see for example Kelly 1991, 1993, 1997; and Lal 1985. Research on the contemporary conditions of women's labour in Fiji often includes discussions of Indo-Fijian women's work. For analyses of women's paid labour in Fiji, see for example Leckie (2000) and, on women garment workers, Harrington (2004).

13 One exception I have found among the plethora of references to Scarry in medical anthropology and in the anthropology of suffering has been Mehta's work on circumcision, violence, and Muslim identity which draws specifically on Part II of Scarry's text (Mehta 1997).

\section{REFERENCES}

1996 Census of Fiji, General Tables - Population, Bureau of Statistics, Suva, Fiji.

Abramson, A. 2000 'Bounding the Unbounded: Ancestral Land and Jural Relations in the Interior of Eastern Fiji', in A. Abramson and D. Theodossopoulos (eds) Land, Law and Environment: Mythical Land, Legal Boundaries, London: Pluto Press: 191-210.

Brenneis, D. 1984 'Grog and Gossip in Bhatgaon: Style and Substance in Fiji Indian Conversation', American Ethnologist, 11(3): 487-506. 
1990 'Shared and Solitary Sentiments: The Discourse of Friendship, Play, and Anger in Bhatgaon', in C. Lutz and L. Abu-Lughod (eds) Language and the Politics of Emotion, Cambridge: Cambridge University Press.

Brodwin, P. 1992 'Symptoms and Social Performances: The Case of Diane Reden', in M. Delvecchio Good et al. (eds) Pain as Human Experience: an Anthropological Perspective, Berkeley: University of California Press: 77 - 99.

Daniel, E. V. 1996 Charred Lullabies: Chapters in an Anthropography of Violence, New Jersey: Princeton University Press.

Das, V. 1990 'Our Work to Cry: Your Work to Listen', in V. Das (ed) Mirrors of Violence: Communities, Riots and Survivors in South Asia, Delhi: Oxford University Press: $345-398$.

1996 'Language and Body: Transactions in the Construction of Pain', Daedalus, 125(1): 67-91.

Desjarlais, R.R. 1992 Body and Emotion: The Aesthetics of Illness and Healing in the Nepal Himalayas, Philadelphia: Univ. of Pennsylvania Press.

Gill, K. 1988 Health Strategies of Indo-Fijian Women in the Context of Fiji, unpublished PhD thesis, Department of Anthropology, University of British Columbia, Vancouver, Canada.

Good, B.J. 1992 'Body in Pain: The Making of a World of Chronic Pain', in M. Delvecchio Good et al. (eds) Pain as Human Experience: an Anthropological Perspective, Berkeley: University of California Press: 29-48.

1994 Medicine, Rationality, and Experience: An Anthropological Perspective, Cambridge, England: Cambridge University Press.

Harrington, C. 2004 ' 'Marriage' to Capital: The Fallback Positions of Fiji's Women Garment Workers', Development in Practice, 14(4): 495-507.

Jackson, J. 1994 'Chronic Pain and the Tension Between the Body as Subject and Object', in T. Csordas (ed) Embodiment and Experience, Cambridge: Cambridge University Press: 201-228.

Kelly, J. D. 1991 A Politics of Virtue: Hinduism, Sexuality, and Counter-colonial Discourse in Fiji, Chicago: University of Chicago Press. 
1992 'Fiji Indians and 'Commoditization of Labor", American Ethnologist, 19(1): 97-120.

— 1993 ' 'Coolie’ as a Labour Commodity: Race, Sex, and European Dignity in

Colonial Fiji, Journal of Peasant Studies, 19 (3\&4): 246-267.

1997 'Gaze and Grasp: Plantations, Desires, Indentured Indians, and Colonial Law in Fiji, in L. Manderson and M. Jolly (eds) Sites of Desire, Economies of Pleasure: Sexualities in Asia and the Pacific, Chicago: University of Chicago Press: 72-98.

1998 'Aspiring to Minority and Other tactics Against Violence', in D. C. Gladney (ed) Making Majorities, Stanford: Stanford University Press.

Kelly, J.D. and M. Kaplan 2001 Represented Communities: Fiji and World Decolonization, Chicago: University of Chicago Press.

Kleinman, A. 1986 Social Origins of Distress and Disease: Depression, Neurasthenia, and Pain in Modern China, New Haven: Yale University Press.

1992 'Pain and Resistance: The Delegitimation and Relegitimation of Local Worlds', in M. Delvecchio Good et al. (eds) Pain as Human Experience: an Anthropological Perspective, Berkeley: University of California Press: $169-197$.

Lal, B.V. 1985 'Kunti's Cry: Indentured Women on Fiji Plantations', The Indian Economic and Social History Review, 22(1): 57-71.

1992 Broken Waves: A History of the Fiji Islands in the Twentieth Century, Honolulu: University of Hawaii Press.

2002 'Afterword: The Debris', in S. Trnka (ed) Ethnographies of the May

2000 Fiji Coup, Special issue of Pacific Studies, 25(4):109-116.

2004 'Three Worlds: Inheritance and Experience', unpublished manuscript.

Leckie, J. 2000 'Women in Post-coup Fiji: Negotiating Work through Old and New Realities', in A H. Akram-Lodhi (ed) Confronting Fiji Futures, Canberra: Asia Pacific Press: 178-201. 
2004 'The Qawa 'Epidemic”, in B.V. Lal (ed) Bittersweet: The Indo-Fijian Experience, Canberra: Pandanus Books:191-206.

Mehta, D. 2000 'Circumcision, Body, Masculinity: The Ritual Wound and Collective Violence', in V. Das, A. Kleinman, et al. (eds) Violence and Subjectivity, Berkeley: University of California Press: 79-101.

Mugler, F. 1998 'South Indian languages in Fiji: Language Contact and Attrition', in Proceedings of the Second International Conference on Oceanic Linguistics (SICOL), University of the South Pacific, Suva, Fiji, 3-7 July 1995. Vol. 1, Language Contact. C-141, Canberra: Australian National University: 95-108.

Oakley, A. 1974 The Sociology of Housework, Oxford: Oxford University Press.

Romero, M. 1992 Maid in the U.S.A, New York: Routledge.

Salusalu, M. 2000 Lecture on over-crowding in the Nausori Health Centre, Nausori Health Centre, April 27, 2000.

Scarry, E. 1985 The Body in Pain: The Making and Unmaking of the World, Oxford: Oxford University Press.

Trnka, S. 1999. "Global Spaces, Local Places: The Body and Imagination in IndoFijian Fiction." SPAN. (Journal for SPACLALS, the South Pacific Association for Commonwealth Literature and Language Studies). University of Waikato, New Zealand. Vol. 48/49: 40-52.

- 2002a 'Introduction: Communities in Crisis', in S. Trnka (ed) Ethnographies of the May 2000 Fiji Coup, Special issue of Pacific Studies, 25 (4): 1-8.

- 2002b 'Foreigners at Home: Discourses of Difference, Fiji Indians and the Looting of May 19', in S. Trnka (ed) Ethnographies of the May 2000 Fiji Coup, Special issue of Pacific Studies, 25 (4): 69-92.

-2002c God Only Listens to Those Who Sweat: Violence, the Body and Community in Sanatan Hindu Dialogues of the May 2000 Fiji Coup, Unpublished $\mathrm{PhD}$ thesis, Department of Anthropology, Princeton University, Princeton, N.J.

2004 'Upahar Gaon', in B.V. Lal (ed) Bittersweet: The Indo-Fijian Experience, Canberra: Pandanus Books:135-150. 
Article $\cdot$ Trnka

_ In press 'Land, Life and Labour: Indo-Fijian Claims to Citizenship in a Changing Fiji' in E. Hermann and W. Kempf (eds) Relations in Multicultural Fiji: The Dynamics of Articulations, Transformations and Positionings, Special issue of Oceania.

— n.d. 'Languages of Labor: Negotiating the 'Real' and the Relational in IndoFijian Women's Expressions of Body Pain', unpublished manuscript. 